\title{
Escola como disputa: juventude e cultura escolar em contextos de ocupação (Rio de Janeiro/2016)
}

School as Dispute: Youth and School Culture in Occupation Contexts (Rio De Janeiro / 2016)

\author{
Alessandra Nicodemos* \\ Ana Carolina Oliveira Alves** \\ Henrique Dias Sobral Silva***
}

\begin{abstract}
RESUMO: As ocupações de escolas públicas no Rio de Janeiro ocorreram no ano de 2016 e empreenderam um novo processo de entendimento dos jovens a respeito da escola e de sua estrutura de organização e direção. O objetivo foi mapearmos as formas de aproximação entre cultura juvenil e cultura escolar e, ainda, os sentidos de origem dos ocupantes, mobilizado por meio produções acadêmicas interdisciplinares sobre o tema. Recorremos dessa forma às metodologias dos grupos focais e à revisão bibliográfica da literatura especializada, cotejando-as na busca de um entendimento mais plural das referidas ocupações considerando, principalmente, os projetos e as vozes dos estudantes envolvidos. A conclusão é que as ocupações foram, antes de tudo, um momento de tensão etntre a cultura juvenil e a cultura escolar, alimentando-se e negando-se ao longo desse processo. Avaliamos, além disso, que as análises acadêmicas acerca do fenômeno devem reforçar as problematizações a partir de categorias internas ao movimento que, longe de fragilizá-lo, sublinham suas especificidades.
\end{abstract}

Palavras-chave: Ocupação de Escolas. Cultura juvenil. Cultura escolar.

\section{SCHOOL AS DISPUTE: YOUTH AND SCHOOL CULTURE IN OCCUPATION CONTEXTS (RIO DE JA- NEIRO / 2016)}

ABSTRACT: Public Schools' occupations in Rio de Janeiro took place in 2016 and they undertook a new process concerning the understanding of teenagers towards school and its structures, organization and direction. Our goal was to track down the different connections between youth culture and scholar culture and the meanings of the starting point for students' rise up, inspired by interdisciplinary academic papers on this topic. Therefore, we invoked the methodologies of focus group and bibliographical review of specialists in comparison. Hence, we look forward to a plural understanding of such occupations, considering students' projects and what they have to say as a priority. Our conclusion is that the occupations were, first, a moment of friction between scholar culture and youth culture, with appropriations and rejections throughout this process. In our evaluation, besides that, academic analysis on this phenomenon must reinforce the issues through the movements' internal categories. In any way, the analysis can make their categories more fragile. On the contrary, they underline their specificities.

Key Words: School Occupations. Youth Culture. Scholar Culture.

* Doutora em Educação. Docente da Universidade Federal do Rio de Janeiro. E-mail: alenicodemosufrj@gmail.com Orcid: https://orcid.org/0000-0001-8287-9116

** Doutoranda em História pelo Programa de Pós-graduação em História (PPGH) Unicamp. Bolsista Fapesp.

E-mail: anacarolinaoa@hotmail.com Orcid: https://orcid.org/0000-0002-6987-5433

*** Doutorando em História (PPGH-UFMG), mestre na mesma área pela UFRRJ (2015-2017) e possui graduação em História pela Universidade Federal do Rio de Janeiro (2010-2015). E-mail: henriq_sobral@hotmail.com 


\section{Introdução}

Esse artigo é um dos resultados da pesquisa Escola como disputa: juventude e cultura escolar em contextos de ocupação (Rio de Janeiro/2016), empreendida pelo coletivo de pesquisa Juventude, Desigualdade Social e Educação de Jovens e Adultos (COLEJA-UFRJ). Nossa agenda de estudos reuniu, por meio da metodologia de grupo focal, estudantes que ocuparam escolas públicas no Rio de janeiro com o objetivo de colher informações sobre a construção das ocupações e os sentidos atribuídos pelos jovens durante e depois daquele momento. No presente artigo, como um recorte da pesquisa, nosso objetivo é entender as origens das ocupações, bem como as relações entre cultura escolar e cultura jovem através de um diálogo em que serão cotejadas impressões dos ocupantes com as dos pesquisadores que se dedicaram à análise do tema.

O movimento de ocupação promoveu a abertura de um novo campo de possibilidades na experiência política brasileira, relacionado à construção de espaços de autonomia e organização vivenciados por esses jovens a partir de reivindicações sobre a educação formal e as instituições de ensino. A escola, entendida em seu espaço material e simbólico, é assediada por diferentes projetos de sociedade e de educação que ultrapassam as ideias tradicionais características das disputas circunscritas às esferas do governo estadual. A expansão, a qualidade e as características dessa instituição têm sido repensadas pelo poder instituído, o que exige novas formas de educar e novos conteúdos.

Entretanto, esse processo gera resistência a partir de novos tipos de ação, como a que exploramos aqui, que deve ser entendida como forma de reação ao gradativo desmonte sofrido pela educação fluminense nas últimas décadas. Assim, acreditamos na importância de estudar o movimento de Ocupação de Escolas do Rio de Janeiro como forma de compreender as possibilidades de luta política articuladas pelos participantes desse movimento.

Os estudantes de cada escola adotaram dinâmicas próprias respondendo, por vezes, a estímulos específicos de seus contextos escolares, muitas vezes compartilhadas entre grupos próximos geograficamente. Por outro lado, tais iniciativas receberam apoio e solidariedade de outros grupos como ex-alunos, sindicatos, partidos e mesmo universidades. No entanto, ao longo do processo de mobilização mantiveram posturas autônomas com relação aos métodos de luta e ao cuidado com o espaço público institucional. Tais condutas auxiliaram na desmontagem de aparatos repressivos, possibilitando que a empatia pelo movimento crescesse em diversos setores.

Entendendo que, nesse processo, cada um e cada uma dos estudantes e das estudantes foi autor e autora de uma história de luta, organização coletiva e resistência - que merece ser debatida e registrada como uma iniciativa popular realizada por jovens - optamos pela utilização de uma estratégia empírica de análise. Escolhemos o caso do estado do Rio de Janeiro e realizamos uma pesquisa analítica e qualitativa, centrada no contato com os próprios alunos e alunas, em torno de suas ocupações. Optamos por convidar estudantes de mais de uma unidade de ensino para permitir a avaliação da experiência em distintos contextos, executando um balanço entre aproximações e distanciamentos dessas vivências e permitindo explorá-las de maneira mais ampla. ${ }^{1}$

\footnotetext{
${ }^{1}$ Por se tratar de um evento de grande acirramento político no estado do Rio de Janeiro e, em muitos casos, de impactos ainda em construção, acreditamos que teríamos dificuldades de inserção nesses espaços, como pesquisadores, por via institucional. Portanto, a ideia inicial era convidar estudantes de colégios estaduais e conseguir estabelecer diálogo de forma direta com os mesmos, sem a intervenção ou autorização 
A escolha de múltiplas escolas proporciona, ainda, uma análise que comporte diferentes matizes da cultura escolar e da juventude, além de permitir detectar as suas especificidades e o campo de determinação que resulta das práticas construídas por esses polos durante as ocupações. A aproximação com os estudantes ocorreu por meio de contatos estabelecidos com professores e chamadas publicadas em redes sociais. Os primeiros alunos contactados ajudaram no estabelecimento de uma rede que, de maneira gradual, foi incorporando estudantes de distintas situações escolares e geográficas. Optamos pela técnica de grupo focal, uma modalidade de pesquisa qualitativa derivada das entrevistas de grupo que consiste na coleta de informações por meio de interações grupais, ou seja, baseada na comunicação e na interação.

Construímos, então, um roteiro estruturado que nos guiou, a partir de perguntas tangenciais, em três grupos focais realizados com 14 estudantes na intenção de aferir o fenômeno. Consideramos o que esses avaliam como as experiências que adquiriram desse espaço e as relações de aprendizagem que construíram e ainda constroem fora das escolas. ${ }^{2} \mathrm{O}$ material de áudio produzido nos grupos focais foi transcrito respeitando as falas dos alunos, suas ideias, suas narrativas e sentidos, sendo nossa intervenção somente na supressão de palavras repetidas e em ajustes ortográficos. Todo o processo de transcrição foi realizado pelos autores e debatido ao longo dos meses de desenvolvimento da pesquisa, à luz da bibliografia selecionada, de modo a construir uma argumentação crítica sobre o fenômeno e principalmente respeitando a dimensão da centralidade dos sujeitos participantes da pesquisa.

Este artigo dialoga com a escrita da História, pois, estamos aqui nos associando a um tópico clássico do debate de Marc Bloch em "O Ofício do Historiador - Apologia da História" (2001). Momento em que o historiador discute a necessidade de se superar um ídolo das origens, em nome do entendimento dos fenômenos sociais e históricos em si, sem que haja uma busca por um nascimento ou origem que, muitas vezes, não o conforma, nem o identifica. Assim sendo, recuperamos esse debate, com a confiança crítica de que sua reedição pode ser profícua aos pesquisadores no tempo presente.

Nesse artigo faremos um primeiro esforço buscando analisar as questões relativas aos mitos de origem desse fenômeno e sua constante associação com outros movimentos ou contextos, problematizando a importância de pensar na juventude que dele fez parte como autônoma e ativa nos debates sobre a educação pública. Defendemos o afastamento de visões lineares, mecânicas e facilitadoras que atribuem ao movimento características necessariamente herdadas de outros, retirando suas questões específicas e complexas.

$\mathrm{Na}$ segunda parte, dedicamos-nos a refletir sobre as características da resistência estudantil no processo de Ocupação de Escolas, diante das carências das unidades escolares e de suas distintas realidades, além de buscar identificar, nesses projetos de organização coletiva em construção, relações implícitas e explícitas com a cultura escolar. Ambas as partes deste artigo estarão cotejadas com expressões dos próprios estudantes, reforçando nossa posição de que a história das ocupações deve prezar pela sincronia e diacronia, considerando o passado e o presente, não como entidades

das direções das escolas ou da SEEDUC. Todos assinaram um termo de livre esclarecimento no qual concordavam com o convite para participar como voluntários da pesquisa, garantindo-Ihes a identidade preservada e a possibilidade de interromper a participação caso assim fosse desejado.

2 Os grupos focais foram realizados entre outubro de 2018 e abril de 2019, no Instituto de Filosofia e Ciências Humanas da Universidade Federal do Rio de Janeiro, localizado no centro da cidade, com estudantes que ocuparam as seguintes escolas: Colégio Estadual José Leite Lopes - NAVE, Colégio Estadual Visconde de Cairu, Colégio Estadual Compositor Luiz Carlos da Vila, Colégio Estadual Chico Anísio e Centro Integrado de Educação Pública 225 - Mário Quintana, localizados na zona norte e oeste da cidade. 
fixas mas como expressões legítimas das vozes dos sujeitos que construíram e viveram as ocupações.

\section{Revendo o sentido de origem no Ocupação de Escolas}

Em setembro de 2015, a Secretaria de Educação do Estado de São Paulo anunciou uma nova organização da rede estadual de ensino, cujo objetivo era a separação das escolas a fim de que cada unidade passasse a oferecer aulas apenas de uma das etapas educação básica (ensino fundamental I, ensino fundamental II ou ensino médio), a partir do ano seguinte. A proposta gerou protestos de estudantes e pais já que, em sua lógica de reestruturação, previa o fechamento de 93 escolas que seriam destinadas a outras funções na área da educação. As enormes polêmicas geradas pela proposta desenrolaram-se em protestos e desembocaram em um dos grandes movimentos sociais nacionais daquele ano: o movimento de Ocupação de Escolas por parte de estudantes secundaristas paulistas que se posicionavam contra esse processo, que tomou proporções nacionais, alcançando a suspensão do projeto pelo governador Geraldo Alckmin (PSDB) em dezembro do mesmo ano.

Ainda no final de 2015, um outro grande movimento de ocupação teve início, no estado de Goiás, como resposta a uma proposta do governo de Marconi Perillo (PSDB) que objetivava transferir a administração das escolas para entidades filantrópicas - as organizações sociais (OS). $\mathrm{Na}$ prática, os repasses de verbas públicas passariam a ser feitos a tais entidades, responsáveis pela manutenção das instituições podendo, inclusive, contratar professores e funcionários. O movimento cresceu e se espalhou pelo Estado, chegando a alcançar o número de 28 escolas ocupadas no final de janeiro de 2016. No início do ano seguinte ressurgiu, no estado de São Paulo, com envolvimento majoritário das escolas técnicas tendo seu foco, entretanto, sobre questões de responsabilidade do governo estadual, como o fornecimento de merenda. Naquele momento, porém, o movimento inspirava estudantes de outras localidades a adotarem estratégias semelhantes.

As ocupações de Goiás e de São Paulo, portanto, caracterizaram-se por terem sido organizadas contra propostas específicas gestadas pelo poder público naqueles estados. Posteriormente, esse movimento ampliou-se para estados como Ceará, Rio Grande do Sul e Rio de Janeiro que, cada qual a sua maneira, aderiram às ocupações de instituições escolares como estratégia de luta estudantil ao longo daquele ano.

No Rio de Janeiro, os secundaristas deram início a uma onda de ocupações de escolas, que se somou à greve dos professores ${ }^{3}$ na gestão do governador Luiz Fernando Pezão (PMDB), em 2016, chegando a atingir mais de 70 instituições de ensino daquela rede. ${ }^{4}$ Mesmo com o decreto estadual antecipando o recesso escolar para as unidades ocupadas, os alunos reafirmaram a disposição de manter as reivindicações por melhores condições de ensino, obtendo adesão e mantendo as escolas ocupadas por quase quatro meses. O crescimento das ocupações reforçou, naquele quadro, o poder da luta estudantil evidenciando, também, a postura do governo que insistia em veicular

\footnotetext{
${ }^{3}$ Entre as reivindicações dos docentes estava a luta contra o piso salarial de $\mathrm{R} \$ 1.180,00$ dos professores e funcionários, que recebem um vencimento menor que o salário mínimo do Rio de Janeiro.

${ }^{4}$ BORGES, Bernardo. Número de escolas ocupadas cresce 1800\%: Cerca de 76 unidades estaduais estão ocupadas no Rio de Janeiro. Portal Band, 04 mai. 2016. Disponível em: https://bit.ly/2Y67zdP. Acesso em: 23 ago. 2017
} 
opiniões negativas sobre o movimento, intensificando a ofensiva e visando a desocupação das escolas. Porém, destaca-se a significativa capacidade de pressão do movimento estudantil sobre o governo estadual do Rio, sublinhando os estudantes como protagonistas na interlocução com o poder público, em uma negociação que resultou na garantia de alguns avanços para as escolas estaduais fluminenses.

Mesmo com algumas reivindicações gerais, a pauta das ocupações no Rio de Janeiro era local e muito determinada pela realidade de cada escola e suas demandas específicas, como se evidenciou a partir do material de pesquisa. Em comum, podemos considerar que os estudantes posicionavam-se contra a degradação das escolas da rede estadual do Rio de Janeiro, em curso há algumas décadas.

Tal degradação apresenta, como marco significativo, a implementação do Programa Estadual de Reestruturação da Educação (Nova Escola), no governo de Anthony Garotinho (19992002), com a precarização das escolas estaduais e o achatamento salarial de seus docentes. Além disso, esse programa intensificou modificações no trabalho educativo na forma de um aumento do controle pedagógico e da diminuição da autonomia do docente sobre a preparação e a execução de suas atividades. Por outro lado, ocorreu também e, junto a isso, um reforço do trabalho pautado em modelos neoliberais de avaliação do sistema.

Esse quadro agravou-se nas gestões posteriores, gerando um sentimento de descontentamento de docentes e estudantes quanto à realidade das escolas estaduais do Rio de Janeiro. Como consequência, ocorreram diversas greves de professores da rede estadual ao longo dos anos 2000, desembocando em uma das mais longas e vitoriosas, a de 2016, que conjugou ações de docentes e estudantes. Nessa ocasião, durante a negociação para a desocupação das escolas, estudantes e professores fluminenses conquistaram grandes vitórias: eleição direta para diretores, ampliação da carga horária nas disciplinas de Sociologia e Filosofia e fim do Sistema de Avaliação da Educação do Estado do Rio de Janeiro (SAERJ). ${ }^{5}$

Ao longo do exercício de revisão da literatura especializada na discussão das escolas ocupadas foi possível identificarmos interpretações, justificativas e motivações a partir de diferentes olhares sobre a experiência. Nesse momento, notamos que grande parte das pesquisas acadêmicas destinou-se a buscar uma origem comum que conectasse as ocupações com outras lutas e movimentos sociais, a partir de diferentes escalas e circunstâncias, àquelas nascidas no Brasil ou em outras partes do mundo. ${ }^{6}$ Em diversos trabalhos houve tentativas de referendar um sentimento de afinidade direta das ocupações com outros movimentos sociais. Atentos aos esforços dos pesquisadores e pesquisadoras do tema e às especificidades da produção em suas áreas propomos, aqui, a problematização de tal argumentação e, em nossas análises, buscaremos reforçar uma perspectiva ampla que compreenda a pluralidade do Ocupação de Escolas.

Escolhemos nos deter em três pesquisas, respectivamente nas áreas da Educação, Ciência

\footnotetext{
${ }^{5}$ O SAERJ foi implementado pela Secretaria de Estado da Educação (SEEDUC) buscando coletar informações acerca do desempenho escolar dos estudantes. Tal sistema foi alvo de críticas constantes de estudantes e professores por ser considerado pouco efetivo, além de aprisionado em práticas de avaliação do processo de ensino-aprendizagem a partir de um modelo classificatório que valoriza aspectos quantitativos e bonifica escolas com resultados positivos.

${ }^{6}$ Uma crítica a essa busca pela origem das ocupações pode ser vista em ALVES, A. C. O.; SILVA, H. D. S. Como é que isso tudo começou: sentidos de origem das ocupações em escolas estaduais do Rio de Janeiro. 2016. $30^{\circ}$ Simpósio Nacional de História - ANPUH-Brasil, Recife, 2019. Disponível em: https://bit.ly/37FkWoA. Acesso em: 22/02/2020.
} 
da Informação e da Psicologia, privilegiando uma abordagem multidisciplinar. Essas pesquisas, realizadas entre os anos de 2017 e 2019, foram selecionadas a partir de uma análise dos títulos e dos referidos conteúdos. Essa escolha não foi casual já que dialoga com a expansão da análise qualiquantitativa dos trabalhos sobre o tema, com base no acúmulo desenvolvido em investigações anteriores dos autores (ALVES; SILVA, 2018, 2019).

Tendo em vista nosso debruçar sobre outras áreas do conhecimento, vale reforçar os compromissos analíticos advindos da História, nossa formação original. Assim sendo, notamos um constante movimento na História, assim como em outras ciências humanas, de inserção de determinados fenômenos no formato de grandes narrativas contínuas, oferecendo aos leitores uma noção linear, etapista e ordenada de acontecimentos. Essa advertência não é de nossa autoria, mas vem sendo gestada desde o início do século XX e tem por objetivo a não reiteração do que Marc Bloch apontou como um comportamento em que "as origens são um começo que explica. Pior ainda: que basta para explicar" (2001, p. 55). Esse tipo de relacionamento com a escrita da história foi denominado, por Bloch, como o "ídolo das origens," postura metodológica a ser superada na área. Assim, mapeamos os estudos recentes sobre as ocupações para analisar como a pluralidade desse movimento tem sido interpretada e a que tipo de narrativas tais reflexões o vinculam, prevenindo o simples estabelecimento do que seria uma cronologia bem formada sobre as ocupações.

Iniciamos essa análise pelo trabalho de Luiz Augusto Gomes intitulado Jovens trabalhadores-estudantes: a construção da vontade coletiva em experiências de ocupação de escolas (2018). O trabalho de Gomes oferece um novo conceito ainda a ser problematizado pela área de educação - e da Educação de Jovens e Adultos, em especial - e manifesta um sólido apuro no trato das fontes e na análise do tema.

A questão das origens é apresentada na introdução, em uma associação realizada através dos ecos de uma efeméride recente, a Revolução Russa de 1917. A partir desse evento, o autor traça paralelos com a Comuna de Paris (1871) como parte de uma compreensão na qual "o movimento de ocupação de escolas é resultado de um acúmulo histórico de lutas da classe trabalhadora" (2018, p.10). Para nós, tal acúmulo histórico é verdadeiro e compõe uma das bases de uma análise materialista histórica, concepção epistemológica à qual o autor se vincula. ${ }^{7}$ Entretanto, interpretamos que acúmulo não pode ser confundido com origem pois tal vinculação pode fragilizar as experiências e práticas, legadas de um grupo ao outro, como um destino manifesto a ser seguido, a partir de uma origem estática e, muitas vezes, pouco coerente com a construção dos sujeitos em seu tempo histórico.

Por vezes, nem mesmo os próprios sujeitos se vêem como portadores de um vocabulário específico para exprimir tal experiência. O processo pessoal, que se relaciona à condição de classe é atravessado, também, pela experiência coletiva e ambos encontram-se em construção a todo o tempo consolidando, assim, uma leitura específica sobre as ocupações ${ }^{8}$

Na minha visão foi um processo: estou começando a entender o que é a greve dos professores,

\footnotetext{
7 O conceito de jovens trabalhadores-estudantes, criado pelo autor, foi debatido em trabalho anterior: ALVES; SILVA (2016).

8 Tendo em vista que nosso interesse centra-se no conteúdo das expressões dos alunos, optamos por apresentar o texto revisto, onde eventuais vícios de linguagem, erros de gramática, palavras repetidas, neologismos e outras marcas comuns da oralidade foram reparados - uma estratégia, também, de resguardo dos próprios estudantes.
} 
agora estou entendendo o que é a greve dos professores. Então pintou essa palavra na minha mente, algumas pessoas falando. Eu não sabia, nunca parei para pesquisar. De repente, a escola estava ocupada. Para mim, foi mais de uma hora para outra do que um processo, eu não consegui passar por essa etapa inicial de um processo. Depois que ocupou eu já estava ocupando, eu aprendi durante a ocupação. Se fosse colocar em uma palavra, eu acho que aprendizagem, para mim, com certeza aprendizagem. Eu cresci muito ali, de n maneiras possíveis. Eu não via como um processo político porque eu não entendia nem o que era política básica. Eu não sabia porque eu não era nem um pouco instruído. Acredito que até hoje eu não saiba quase nada, sinceramente. Eu acho que eu sei muito pouco, mas, o pouco que eu sei, com certeza foi devido à ocupação. (Aluno A.)9

Não podemos desconsiderar o excesso de informações ao qual aqueles jovens estavam submetidos e as referências podem ter sido captadas como acúmulo individual, coletivo ou até mesmo desconsideradas. Seja como for, o aluno nomeia como aprendizagem a ocupação e seu papel até o tempo presente em sua vida.

Tendo em vista a distância entre a posição do aluno e do autor discutido, avaliamos que o ídolo das origens consiste num perigo interpretativo, pois o ato de leitura - e de produção do autor - transforma-se no acompanhamento de um passado que sustentaria um suposto sentido ao evento mais recente. Tal postura pode esvaziar experiências e potencialidades somente pela inexistência de referências históricas. Não defendemos, por outro lado, a lógica da vanguarda como orientação analítica mas observamos a urgência de uma escrita da história das ocupações que acolha suas circunstâncias a partir de visões, projetos, sonhos e angústias dos sujeitos que dela tomaram parte.

Na sequência, dialogamos com a pesquisa de Andrea Doyle (2018), doutora em Ciência da Informação. A partir dos métodos e técnicas dessa área, a autora discute novas práticas informacionais e educativas desenvolvidas nas ocupações das escolas estaduais do Rio de Janeiro, em uma potente contribuição para os estudos do fenômeno. Nessa oportunidade, voltamo-nos para o tópico Movimentos de protesto e ocupação, que traz uma análise bastante específica sobre as ocupações, em especial as do Rio de Janeiro. ${ }^{10}$

Apoiada em Castells (2013), a autora traça um continuum de manifestações em distintos países, desde o norte da África (Tunísia) até a Islândia, passando pela Espanha e alcançando os Estados Unidos, para construir um quadro de lutas e manifestações pelo mundo em 2016. Nessa empreitada, oferece um rico panorama sobre os movimentos sociais problematizando seus avanços e recuos. Contudo, chamou atenção certa conexão e uma filiação do Ocupação de Escolas a esses fenômenos ocorridos em outros países, como uma decorrência dos mesmos. A autora conclui com a seguinte análise:

Por não terem sido mencionados pelos ocupantes, não sabemos até que ponto esses movimentos foram acompanhados pelos alunos, nem se eles tiveram influência direta nas decisões ou nos detalhes da organização das ocupações. Mas entendemos que, ao menos indiretamente, eles devem ter contribuído, seja sob a forma de suas práticas e conquistas, seja por terem mantido vivo e atualizado o ativismo cidadão face aos excessos de autoridade hierárquica, supressão de direitos sociais e de pressões econômicas exercidos pelas elites político-financeiras

\footnotetext{
${ }^{9}$ A título de preservação dos alunos participantes da pesquisa, optamos por identificá-los com letras.

10 Esse tópico é seguido por Movimentos que inspiraram as ocupações das escolas estaduais do Rio de Janeiro, A Revolta dos Pinguins e A experiência de São Paulo, que merecem análises específicas em textos posteriores, pois aprofundam a crítica exposta pelos autores deste texto.
} 
em nome da (sua) sobrevivência no sistema capitalista global. (DOYLE, 2008, p.50)

Para nós a primeira frase é muito significativa, pois acreditamos que é necessário avaliar o impacto das ocupações a partir dos comentários e considerações dos alunos que podem, devido à sua experiência, elaborar considerações sobre as motivações para as ocupações.

A gente sabia que as ocupações estavam acontecendo, eu tinha visitado o Mendes de Moraes [Colégio Estadual Prefeito Mendes de Moraes], tinha conhecido pessoas e tal, mas não sabia que essa realidade se enquadrava na minha escola. Quando eu soube disso, foi muito desafiador pra mim. Lá foram 32 jovens que decidiram ocupar, então foi muito desafiador, mas ao mesmo tempo, foi muito gratificante porque durante a ocupação, tivemos momentos multiplicadores. (Aluno B.)

No início não estava organizado, eram coisas pontuais, como a caminhada até Del Castilho. Ficava uma coisa muito perdida. Se conversava nos corredores sobre a situação, mas ninguém tinha um foco em ocupar. A gente ainda não tinha conversado sobre isso. Quando começaram as ocupações, eu me lembro que eu tinha uma amiga que disse: "Eu ocupei meu colégio". Então veio a ocupação do Clóvis [Colégio Estadual Professor Clóvis Monteiro], que foi bem importante para puxar a nossa ocupação. (Aluna C.)

A expressão da aluna C. é significativa pois demonstra uma construção da ocupação a partir de experiências da periferia da cidade do Rio de Janeiro, com elementos locais como a passeata no bairro vizinho à escola, na zona norte da capital. Também indica a sociabilidade dos jovens, aspecto próprio de sua cultura que, em suas interações carregam, também, impressões e exemplos que, constantemente, entram em contato direto com seus colegas. Dessa maneira, o modo de ser jovem configura uma importante pista para o entendimento de como se estruturaram e se realizaram as ocupações.

Começamos a fazer coisas na escola. No meio do pátio a gente começou a fazer jogral prá falar pras pessoas o que estava acontecendo nos atos, pra gente conseguir conversar com os estudantes. No dia da ocupação mesmo, a gente estava fazendo uma assembleia e a gente falou com os estudantes, marcou com o diretor de pegar o auditório pra gente fazer a assembleia. Então chegou a METRO e a SEEDUC lá, representantes, e falaram que não ia poder ter assembleia. A gente perguntou: 'Porquê?' e 'Ah porque os estudantes não estão podendo fazer assembleia agora', basicamente falando que a gente não poderia organizar o movimento estudantil. Aí a gente disse, 'A gente pode organizar o movimento estudantil, a gente é estudante, então a gente vai organizar'. Então a gente passou nas salas, correndo, correndo muito, em todas as salas e dizendo: 'Geral sobe, vai ter assembleia a gente vai decidir várias coisas agora'. (Aluna D.)

Os professores de lá não podiam fazer greve porque era uma parceria público-privada, com o Instituto Ayrton Senna. Então estavam começando a viver essa situação. Porque mesmo que eles não pudessem fazer greve, eles não estavam recebendo salário. Então ficava aquela contradição e eles diziam que se fizessem greve seriam expulsos, sair do programa. Então a gente começou a ver sobre isso e começou a conversar com a AERJ [Associação dos Estudantes Secundaristas do Rio de Janeiro] [...] (Aluna E.)

Aqui nota-se que a tomada de consciência da suspensão arbitrária do direito de greve dos professores, supostamente por conta de uma parceria público-privada entre o Estado e o Instituto 
Ayrton Senna, mobilizou os alunos a amplificarem suas críticas às condições de sua escola. ${ }^{11}$ Associado a isso, tal como no caso anterior, a comunicação entre os jovens instaurou um processo crescente de conscientização e, no caso em apreciação, os alunos aproximaram-se de uma iniciativa discente organizada por alunos, comprometida com a representação destes em âmbito estadual. É possível percebermos que o crescimento da indignação e o sentimento de possibilidade de organização e de mudança levou ao acolhimento de práticas como o jogral, as assembleias e a tentativa de estruturação de um grêmio estudantil, culminando com a ocupação.

Esse vocabulário, possivelmente influenciado pelos membros da Associação dos Estudantes Secundaristas do Rio de Janeiro (AERJ), embora possa ser encontrado em outras experiências de movimentos sociais não diminui a potência e o protagonismo dos alunos afinal, são estudantes encontrando e lutando por direitos e pela solução de desafios internos à escola. Nota-se, ainda, a tensão nas frases finais da aluna, demonstrando uma clara fricção entre a cultura jovem e a cultura escolar, tal como analisaremos à frente, em embate aberto naquele momento.

Tal como mencionado anteriormente, essas expressões não fazem alusão, de modo explícito, a outros movimentos sociais. Assim, reforçamos a necessidade de acompanhar mais detidamente as vozes e os relatos dos estudantes para que possamos reforçar nossas leituras e a escrita de uma história das ocupações mais atenta aos elementos que, de fato, tiveram expressão em seu processo.

Ainda em diálogo com Doyle, avaliamos que é necessário apurarmos nossas análises das entrelinhas, dos não ditos e dos silêncios em pesquisas que envolvam pessoas. Desse modo, teremos ferramentas mais potentes para captarmos informações que podem estar perpassadas pelas expectativas e pelos conhecimentos desses sujeitos mas, por algum artifício da memória, foram negligenciadas ou apareceram sublimados frente a outras falas ou histórias. Afinal, devemos nos orientar por aquilo que os sujeitos conheciam, tendo que partir deles a justa medida da construção do fenômeno das ocupações cabendo a nós, como pesquisadores e pesquisadoras, a sensibilidade de acolher e problematizar, à luz da bibliografia, essas expressões e considerações.

Avaliamos que o mesmo esforço deve ser empregado na análise de práticas e conquistas, aspectos em que temos uma leitura distinta da autora quando lança mão de comparações. Interpretamos que a vivacidade e o ativismo dos secundaristas são construídos por experiências nascidas em suas vivências de juventude, de tensão com a cultura escolar e de suas circunstâncias socioeconômicas e de classe e não por "pressões econômicas exercidos pelas elites político-financeiras em nome da (sua) sobrevivência no sistema capitalista global" (DOYLE, 2008, p.50). Frente a essa análise, reforçamos a necessidade de que sejam ouvidos os sujeitos para melhor calibrarmos nossas ferramentas de entendimento sobre as ocupações.

Isso começou lá na greve dos professores e também por causa da mobilização das outras escolas. Nós também somos um colégio estadual, a gente deveria ajudar essas pessoas. O processo de ocupação do NAVE [Colégio Estadual José Leite Lopes] para mim foi um processo de aprendizagem muito grande nisso de poder conhecer as outras escolas, de sair daquele local. A partir disso de conhecer outros lugares a gente começou a montar nossa pauta. Nós começamos a montar a pauta do NAVE durante a ocupação. A gente tinha algumas coisas, no início era: 'a gente precisa ajudar as outras escolas e a gente quer ter eleições diretas para a direção', mas era muito mais poder conhecer e ajudar as outras escolas. (Aluno F.)

\footnotetext{
${ }^{11}$ Caso específico da Escola Estadual Chico Anysio
} 
O aluno F. reforça a argumentação de apoio discente à greve dos professores e expressa, um importante elemento, a solidariedade. Sob a lógica de ajudar e conhecer demonstra, como certa bibliografia sobre o tema já mostrou claramente, que o espaço das ocupações constituiu, também, um lugar de trocas entre estudantes de distintas escolas e que essas relações estruturaram-se baseadas na colaboração e na ajuda mútua, com o objetivo de reforçar as pautas internas e coletivas.

Em outro espectro de investigação, agora na área da psicologia escolar e do desenvolvimento humano, temos o trabalho de Nicole Oliveira intitulado "Por uma democracia para a educação: autonomia, liberdade e governo de si nas ocupações secundaristas de São Paulo". A autora investigou o movimento de ocupações das escolas públicas do estado de São Paulo por estudantes secundaristas, iniciadas no ano de 2015, com destaque para as escolas estaduais Fernão Dias Paes e Diadema, primeiras ocupadas naquele estado. Munida do objetivo de analisar as características do movimento no que diz respeito às práticas do cotidiano na escola ocupada, a buscou estabelecer relações com postulações teóricas referentes a interações sociais baseadas em processos democráticos e de autogoverno, executando uma extensa releitura de clássicos sobre o tema nas ciências humanas. ${ }^{12}$

A despeito do importante exercício de sistematizar parte da bibliografia sobre as ocupações, no item Contexto nacional e internacional pré-ocupações secundaristas, a autora dedica-se a mapear, a partir dessa bibliografia, as origens do movimento de ocupações. Nesse exercício de apresentação da bibliografia notamos o interesse em realizar uma possível arqueologia das origens das ocupações que, em realidade, limita-se a inserir parâmetros de comparação e filiação da experiência dos secundaristas brasileiros.

Isso posto, a revisão bibliográfica objetivou identificar a produção mais recente acerca das escolas ocupadas, de modo que fosse possível, ao leitor, ampliar seus conhecimentos sobre o tema, além de subsidiar novas discussões. Defendemos essa posição como um compromisso com o movimento em seu entendimento em si, sem que sobre ele paire a demanda e a responsabilidade sobre uma origem que não é sua e que não é recuperada pelos sujeitos que o construíram.

Avaliamos que uma forma de evitar os riscos de uma leitura harmônica e bem encadeada das ocupações, imersa em uma suposta raiz comum e única, é analisar o fenômeno sobre outro paradigma. Para isso, é necessário encarar as ocupações como problema histórico, de modo que a importância repouse na questão a ser formulada e respondida pelo pesquisador e não em recortes temporais distantes do real, que muitas vezes não podem ser estabelecidos a priori.

\section{A Cultura Escolar entre reprodução e transgressão no contexto das ocupações}

A partir da categoria cultura escolar pretendemos indicar, no processo histórico, político e educacional em tela, os níveis de reprodução e transgressão que a juventude experienciou no processo de Ocupação de Escolas. Temos, por um lado, a cultura escolar com suas práticas abran-

12 Destacamos John Dewey e Jean Piaget, bem como Michel Foucault, em suas considerações sobre educação, resistência e governo de si. 
gentes, portadora de suas próprias formas de ação e juízo, baseadas em um modus operandi cristalizado historicamente em sua organização e gestão, bem como nas práticas mais cotidianas nos espaços escolares que, com as ocupações, eram confrontados abertamente. Por outro, a juventude das escolas estaduais que experimentava a precariedade desigual das condições de infraestrutura e o peso da hierarquia escolar, naquele momento lançava mão, abertamente, de outras formas de ação coletivas, horizontais e, em alguma medida, distantes daquela cultura escolar que vivenciavam.

A categoria cultura escolar precisa ser balizada, neste estudo, por dois debates centrais. $\mathrm{O}$ primeiro consiste no reconhecimento da experiência da escolarização a partir do século XX em países do sul como o Brasil - é nesse século que ampliamos a experiência escolar para sujeitos e grupos sociais até então impedidos e a escola tornou-se uma experiência universal, pública e obrigatória. Essa garantia, que se estrutura de forma desigual, precária e com limitados recursos ao longo das décadas do referido século, desembocou em uma ampliação que fragilizou, de forma central, o modelo de escola a ser oferecido e consequentemente forjou, no seu interior, diferentes padrões de cultura escolar. Mônica Peregrino (2009, p. 54) afirma que se constitui, nesse processo, uma dinâmica de 'mais escolas sendo menos escola' e, no caso da rede estadual de educação do Rio de Janeiro, esse quadro é bastante significativo pois a precarização dessa oferta apresenta-se de forma emblemática e deflagradora dos movimentos de ocupação de escola em questão. Para a autora constitui-se, em muitas experiências escolares, modos distintos de escolarização: um modo precário ou um modo pleno de escolarização.

Nesse caso não podemos perder de vista que as cultura escolares que se estabelecem nessas duas experiências serão, também, distintas rompendo, no contexto das ocupações, com o paradigma de um modelo de cultura escolar único ou majoritário na rede estadual do Rio de Janeiro a partir de sua ampliação. Nessa diversidade identifica-se claramente, na narrativa dos estudantes mobilizados pela pesquisa que, em alguns casos, existia a exigência e o rigor para e sobre os processos de ensino e aprendizagem, bem como sobre os resultados. Já em outros, predominavam práticas repressivas e de reprodução mecânica das regras disciplinares, com pouca centralidade nos processos de ensino e aprendizagem dos conhecimentos escolares. No Rio de Janeiro teremos escolas caracterizadas por ambas experiências de cultura escolar, ou seja as reivindicações, nessa lógica aparentemente contraditória de realidades escolares, demonstram que a maior demanda da juventude consistia na construção de espaços de exercício de poder juvenil e de participação mais efetiva nas dinâmicas escolares.

Sabe quando você chega perto de um ninho de baratas e quando você chega as baratas somem? [...] O pessoal tinha medo da diretora e a gente achava isso um absurdo. [...] era bastante aquela comparação que se faz com a prisão e a escola, sabe? (Aluno G.)

No caso da minha ocupação teve uma questão que eu acho que nenhuma outra escola teve: a gente tirou a diretora e colocou o professor de filosofia, o cara que tinha o maior projeto pedagógico e que transformou o colégio [...] O projeto dele não tinha essa coisa de autoridade, não tinha autoridade em sala. Ele tirou o sino que tocava para gente entrar e sair da sala de aula. Ele queria realmente colocar a responsabilidade na mão dos alunos. Ele queria que os alunos fossem donos do colégio, porque os alunos sempre são usados como uma massa que você vai comandando. Ele achava isso completamente absurdo. (Aluno H.)

A cultura escolar estrutura-se, organiza-se, modifica-se e se estabiliza em exercícios de 
poder organizados e traduzidos, segundo Tardif (2009) em duas espécies: a primeira, o poder sócio político de funcionários, ministros e políticos e, ainda, de grupos de pressão, como pais e associações religiosas, dentre outros, que atuam de fora para dentro da escola. Por outro lado, o poder de especialistas, gestores e professores que o exercem no interior da escola.

Nessas duas espécies de exercício de poderes que, em algumas vezes, se confrontam, a juventude sofre condicionamentos de toda ordem: a cultura escolar vai se amalgamando ao longo do tempo, a partir dessa dinâmica, por vezes autoritária, por vezes mais democrática, mas que apresenta uma pequena possibilidade de interlocução com as demandas da juventude e pouco espaço de abertura e de escuta. A experiência das ocupações dispõe, sobre essa estrutura de divisão de poderes, um novo sujeito político coletivo, que também reivindica seus espaços de exercício e de construção de poder. Tais estudantes aproximavam-se dessa nova possibilidade de inserção no espaço escolar na experiência das ocupações através de rotinas básicas como a limpeza, a preparação da comida e de materiais de divulgação, além da participação em reuniões deliberativas, atitudes que promoveram a democratização e a horizontalização do poder.

Eu me lembro que parecia um Big Brother. Você vai morar dentro de uma casa, com pessoas com vidas totalmente diferentes da sua, com criações diferentes da sua, mas, no fundo, nós tínhamos o mesmo propósito. Mas éramos pessoas com personalidades distintas. Eu lembro que começamos a separar as comissões, tinha comissão da limpeza, da segurança. Me lembro de falar assim: 'Não, eu vou ficar na limpeza' (Aluna C.)

O que eu aprendi muito lá é como as pessoas se organizam. Nós nos organizávamos em comissões, tinha a comissão de segurança que ficava vigiando o portão. Tinha a planilha deles: esse horário fica você e esse horário vai ficar cicrano. Tinha a galera que cuidava da alimentação, a galera que cuidava das atividades [...] (Aluno F.)

A descoberta de recursos e materiais em meio a esse processo, bem como a apropriação do espaço escolar, foram essenciais para instaurar uma nova dinâmica nas relações que se estabeleciam. Tais relações foram marcadas por uma profunda preocupação em ressignificar as escolas e o processo educacional, transformando-os em temas de um debate público preocupado em discutir tanto sua estrutura quanto seu funcionamento.

Lá antes era mais focado para a música, tanto que tinham umas oficinas de música, percussão, tinha instrumentos, piano... No início, nos primeiros anos do colégio, ele foi usado. Só que depois esconderam. Tinha gente que nem sabia que tinha um piano lá. Quando eu entrei e a gente abriu a sala foi uma surpresa, nossa tinha um piano! A gente achou vários outros instrumentos. (Aluno I.)

O [Colégio Estadual Visconde de] Cairu é enorme: tem duas quadras, tem uma quadra interna com um palco, dentro desse palco tem uma passagem subterrânea com salas, salas que eram usadas antes... [...] Nossa, tinham várias atividades lá [...] Quando nós achamos as chaves, tinham livros apodrecendo (Aluna D.)

Nessas experiências de exercício de poder destaca-se o rompimento com dois elementos centrais da cultura escolar: de início, a prevalência quase exclusiva do código escrito como veículo de transmissão e de tradição. Em segundo lugar, a opção pelos conteúdos sujeitos a uma tradição escolar eurocêntrica e distante dos educandos e de uma realidade histórica latino-americana com fortes traços multiculturais em sua formação histórica, como é o caso do Brasil. Destacamos esses 
dois elementos muito marcados na sedimentação da cultura escolar pois a narrativa dos educandos indica, claramente, o rompimento com essas duas experiências nas dinâmicas organizativas da Ocupação de Escolas.

A cultura escolar, segundo Tardif, impõe-se como cultura escrita:

A escola moderna é um ambiente cultural e socialmente separado do universo ambiental, um ambiente formal regido por exigências que tem muito pouco a ver, geralmente, com a realidade familiar e social. Historicamente, a expansão da escolarização está ligada à edificação de uma cultura e de saberes escritos que apresentam um alto grau de abstração em relação aos saberes locais das comunidades e à cultura diária: são saberes objetivados, codificados, formalizados; seus modos de transmissão e de apropriação são objeto de procedimentos delimitados e regulamentados (TARDIF, 2009, p. 75)

As práticas escritas como espaço de transmissão e sedimentação de uma determinada organização escolar foram bastante fragilizadas, bem como o uso central da escrita nos processos de ensino e aprendizagem que continuaram a se desenvolver na escola durante as ocupações. Nessa dinâmica a oralidade alcançou destaque pois a nova cultura escolar reinventada no processo das ocupações usava, principalmente, a prática das assembleias e reuniões como veículos de construção das tradições e do modo operacional daquela experiência. Tais assembleias eram diversas, dinâmicas e longas e se constituíam como centro da organização.

Uma importante característica é que não se desenvolviam práticas significativas de registros dessas experiências orais de disputa e entendimento político. A força de uma decisão, às vezes exaustivamente discutida, ganhava o status de um código disciplinar escrito - aquele normalmente mobilizado por gestores e professores em práticas escolares e invariavelmente transgredido pelos estudantes. Nesse caso, é emblemático como a oralidade se sobrepôs à prática escrita de forma muito mais hábil e significativa. Mas o que se destaca nessa disputa é que os educandos tinham real papel de participação e decisão levando-nos, inevitavelmente, a indagar porque não construímos no interior das práticas escolares mais exercícios de oralidade disputadas e discutidas e menos práticas de códigos escritos autoritários e verticalizados.

Acho que isso despertou, mais ainda, essa vontade de ocupar. Esse grupo de pessoas montou uma comissão para discutir sobre isso. Falou, passou em todas as salas, pra gente tentar fazer uma assembleia sobre, para que a gente pudesse deliberar sobre uma paralisação ou não. Deu um tempo e, no dia que a gente saia mais cedo, nos encontramos porque era importante para a escola, para todas as escolas, para a educação como um todo e então a gente ocupou. Sentamos na assembleia e rolou a ocupação (Aluno A.)

[...] tinha divergência, várias... Se não me engano a gente fez quatro reuniões gerais, ás vezes era um caos, porque era muita gente. Era todo mundo gritando, querendo falar. O pessoal nunca tinha vivido uma assembleia, a primeira assembleia foi no colégio. Isso era uma Babilônia em chamas (Aluno J.)

Nós queríamos aproveitar o momento em que os alunos saíam das salas para dizer: 'Fica aqui, escuta o que a gente tem pra falar'. O diretor disse que não, não deu motivos e fechou o auditório. Aquilo chamou mais atenção, porque a partir do momento em que você é impedido de estar no seu espaço é estranho. Se eu estudo nesse espaço como eu não posso fazer uma assembleia aqui dentro? [...] A partir do momento em que ele deixou a gente do lado de fora, a comunidade percebeu que alguma coisa estava errada. Imagina só um monte de alunos sentados em roda, uma coisa que nunca tinha sido vista antes. Nós estávamos conversando com 
alto-falante, começaram a chegar pessoas... (Aluna C.)

Até que durante a primeira assembleia, um aluno negro, $\mathrm{Y}$, relatou que o diretor foi dar um informe na sala, e durante esse informe, o Y meio que discutiu com ele, não aceitando, e ele simplesmente pediu pro policial pegar ele pelo colarinho e tirar ele de sala. (Aluna C.)

$\mathrm{Na}$ dimensão dos processos de mobilização do conhecimento formal como experiência de aprendizagem temos, novamente, rompimentos significativos nas práticas desenvolvidas pelos estudantes. A ruptura inicial mira a própria organização disciplinar dos conhecimentos, separados e sistematizados nos currículos escolares e integrantes de umas das tradições mais arraigadas na experiência de escolarização formal: as disciplinas escolares. Essas disciplinas remontam a tradições que vão desde a antiguidade greco-latina até as tradições curriculares europeias do século XIX, com destaque para a escola francesa (CHIZZOTTI; PONCE. 2012).

Dessa forma, os processos de construção e reavaliação curriculares no Brasil, ao longo da expansão da escola, não foram acompanhados por uma atualização que procurasse dialogar com as especificidades nacionais ou latino-americanas de cultura e conhecimento ou, ainda, com determinantes históricos e políticos de uma escola pública fragilizada em suas dimensões estruturais e de pessoal. Nessa direção, o longo tempo das tradições curriculares produziu um conhecimento que "não cultivou, inicialmente, estudos acerca da compreensão do papel da escola, preocupandose apenas em buscar racionalmente formas de atender demandas econômicas imediatas e produzir um pensamento único homogêneo pretensamente neutro" (CHIZZOTTI; PONCE. 2012, pg. 27). Essa tradição curricular homogeneizada mostrou-se insuficiente para a construção e a divulgação de conhecimento por parte dos estudantes nas ocupações e, dessa maneira, as possibilidades de mobilização de conhecimento tiveram que ultrapassar esse cânone eurocêntrico curricular e disciplinar:

Variava muito, principalmente nas duas primeiras semanas, aconteciam várias paradas, rodas de conversa todos os dias, um pré-vestibular social, muita coisa acontecendo. (Aluno G.)

Tinha oficina de música e essas pessoas que participavam começaram a participar e perceber: 'Eles estão fazendo alguma coisa'. E começaram a perguntar. Os alunos da noite também e nós começamos a colocar pautas e reivindicar nosso espaço (Aluna C.)

A galera precisa passar no ENEM, a maioria dos ocupantes era do terceiro ano. Então a gente pensou: vamos chamar professores. Os melhores alunos vão dar essas aulas aqui nesses horários. Vamos chamar professores para dar aula disso e disso. E vamos também pensar como a gente vai dar aula. A gente tem que dar aula para as pessoas do lado de fora também. A gente parava a rua para dar aula para as pessoas, para dar aula para quem quisesse estar ali. [...] A gente deu aula de nazismo no meio da rua. (Aluno H.)

[...] rolavam eventos, convidavam professores prá dar aula, tinha toda uma grade semanal que rolavam eventos e várias coisas. Eles tentavam fazer uma escola como se deveria ser uma escola, eu acredito, né? Eu comecei a entender que aquilo deveria ser uma escola, diferente do que era antes da ocupação [...] porque, eu acho que escola é as pessoas estarem em um lugar onde elas querem, diferente do que era antes, antes da ocupação. Antes era um lugar comum, antigo, bem antiquado, que nem todo mundo se sentia pertencente e na ocupação muita gente passou a se sentir pertencente, dentro daquela escola. (Aluno A.)

Eu escolhi ressignificar porque eu acho que, na verdade, foi muito isso, nós tivemos que ressignificar um espaço que para a maioria das pessoas que participaram da ocupação elas são e 
eram pessoas que, de alguma forma, o ambiente do colégio marginalizava elas, então, é bom a gente pensar que, quem ocupou o colégio não era aquele aluno que estava lá todo dia, era aquele que a galera ficava 'pô, ele nem vem pro colégio'. Eu mesmo, na época do colégio, eu era bem mais empenhado, digamos assim, e eu era uma das pessoas que falava isso, mas eu também acho que a ocupação não teria acontecido se essas pessoas não tivessem tido essa iniciativa de falar: 'Eu vou ressignificar isso!' (Aluno K.)

A realização de aulões públicos, rodas de conversas e debates que contaram com a participação de agentes externos à escola (professores universitários, sindicalistas, artistas e público em geral) possibilitou uma diversidade de temáticas que serviu como elemento de mobilização dos estudantes a fim de participar e compartilhar saberes e conhecimentos que dialogavam, decididamente, com suas angústias existenciais, seus lugares de classe, de raça, de gênero, de orientação sexual e, principalmente, de moradores da periferia. E mesmo com essa transgressão temática e política, reafirmam o lugar da escola ocupada como espaço de aprendizagem, mas agora encaram positivamente tal experiência, já que a mesma aproxima-se de suas vidas, em sentido amplo e de sua condição juvenil, em sentido específico.

\section{Considerações Finais}

O processo de Ocupação de Escolas foi um dos mais significativos fenômenos políticos do Rio de Janeiro nas décadas iniciais do século XXI principalmente por ter mobilizado, como protagonista, uma juventude engajada. Consideramos que, nesse processo, delineia-se um contexto no qual as instituições passam a ser reivindicadas como espaços de construção vistas de baixo, ou seja, pelos alunos. ${ }^{13}$ Assim, as ocupações configuraram-se em um espaço formativo de construção, mostrando a importância de debater as diferentes dimensões da vida social e escolar de seus sujeitos. Faz-se importante, portanto, compreender as ações dos estudantes em suas dimensões subjetivas e políticas, já que essas ocupações representaram um movimento no qual os estudantes expuseram suas próprias demandas, transformando a escola em um espaço de diálogo sobre assuntos que acreditavam que deveriam ser debatidos - por isso se organizaram e por isso lutaram. Esse movimento colocou a escola pública - suas estruturas, suas relações de poder e o modelo de sucateamento - como pauta política a ser debatida no âmbito educacional mas, também, na sociedade como um todo.

Consideramos, assim, que os processos de Ocupação de Escolas constituíram-se em significativo espaço de materialização de novas perspectivas para a relação da juventude com a cultura escolar, na mirada de conceber a escola como um locus de disputa entre modos de ser aluno e modos de ser jovem. Apoiada em Dayrell (2003), analisamos (Nicodemos, 2017), a relação entre juventude e cultura escolar na perspectiva de uma tendência da escola e de seus profissionais de considerarem a juventude em processo de escolarização em uma dimensão de transitoriedade, de

\footnotetext{
${ }^{13}$ Aludimos aqui ao movimento historiográfico surgido na década de 1960 com o alargamento teórico da disciplina proposto pela Escola dos Annales que se convencionou chamar de history from below. Essa perspectiva, surgida nos estudos ingleses de autores como Edward Palmer Thompson, Nathalie Zemon Davis e Christopher Hill, propunha um deslocamento crítico que se manifestava na análise de práticas e formas de ação das camadas populares, geralmente negligenciadas ou excluídas das narrativas historiográficas.
} 
um vir a ser. Portanto um modo de ser jovem precisa ser, através dos contingenciamentos da cultura escolar e da pressão pela certificação e pelo sucesso, controlado, silenciado ou neutralizado, na aposta de que o período da juventude consiste numa etapa a ser superada pela fase adulta, pela maturidade e por uma futura inserção social com maior responsabilidade.

Consideramos, a partir das reflexões suscitadas por esse trabalho, a juventude mobilizada na Ocupação de Escolas do Rio de Janeiro não como sujeitos de um vir a ser, mas agentes do tempo presente, da ação, da resistência, dos sonhos, das contradições, da responsabilidade, dos erros, do compromisso e da luta e que, em análise retrospectiva, tem muito a nos dizer sobre a escola, a cultura escolar e o ser jovem, como observamos nos trechos abaixo:

[...] eu era o aluno merda, medíocre que só faz besteira, que tá away da vida [...] o cara que parou, pensou um pouco, organizou suas ideias e tá chegando na cara da diretora que sempre subjugou - que já olhava diferente, cobrava de você o que não cobrava de outro aluno. Pra mim, chegar na cara dela e falar: 'Minha escola, você vai ter que sair agora.', foi a melhor coisa que eu podia fazer, sabe!? (Aluno G.)

Sempre foi aquilo: o diretor lá em cima, os professores lá em cima dentro de sala e os alunos só entravam em sala, ouviam o que o professor estava falando [...] Não sei se na escola de vocês tinha grêmio estudantil? Na minha a gente não conseguia formar um grêmio, porque o diretor escondeu o estatuto. Uma coisa que é direito nosso, se organizar enquanto estudante. (Aluna C.)

Dentro de qualquer espaço a gente tem hierarquia, que são preestabelecidas de acordo com características que as pessoas carregam, com as questões de onde a pessoa nasceu, como a pessoa se apresenta naquele espaço, como aquele espaço é capaz de abraçar aquela pessoa ou cuspir pra fora dele. Eu acho que o que acontecia, para a maior parte dos alunos do [Colégio Estadual] Visconde de Cairu, era não gostar de estar em sala de aula muito por causa desse sistema de ensino que todo mundo sabe que é arcaico, do século XIX, com professores com mentalidade do século XX e alunos do século XXI. Tinha tudo e tem tudo para permanecer dando errado. Com o movimento de ocupar o colégio, de ressignificar aquele espaço, as pessoas conseguiram, de alguma forma, tomar um espaço que há muito tempo não era de ninguém. A gente fica muito com essa noção do Estado, quem é o Estado? Onde o Estado está? Então eu acho que, levantando todas essas questões, a galera que, até então, era tida como incapaz, conseguiu ressignificar o sentimento pelo meio, pelos outros, esse sentimento que era real dentro do colégio. (Aluno K.)

Nessas experiências emergem diferentes formas de relações políticas cotidianas que revelam, para esses jovens, questões de participação e novas práticas sociais, em um contexto onde a luta política confere ao ensino, e à escola em particular, um caráter de disputa no qual esses estudantes assumem papéis centrais. Suas vozes precisam ser mais ouvidas e, principalmente, reverberadas nas relações que a cultura escolar continua a promover no interior das instituições de ensino possibilitando, assim, que o modo de ser jovem - que, nas experiências de ocupações, prevaleceu em detrimento das normativas da cultura escolar - contribua para a construção de relações escolares mais plurais, mais humanas, mais juvenis, mais transgressoras e, com isso, potencialmente construtoras de uma outra escola, verdadeiramente emancipatória para nossa juventude.

\section{Referências}

ALVES, A. C. O.; SILVA, H. D. S. Como é que isso tudo começou: sentidos de origem das ocupações em escolas estaduais do Rio de Janeiro. 2016. $30^{\circ}$ Simpósio Nacional de História - ANPUH-Brasil, 
Recife, 2019. Disponível em: https://bit.ly/37FkWoA. Acesso em: 22/02/2020.

BLOCH, M. Apologia da História ou o Ofício do Historiador. Rio de Janeiro, Jorge Zahar, 2001.

BORGES, Bernardo. Número de escolas ocupadas cresce 1800\%: Cerca de 76 unidades estaduais estão ocupadas no Rio de Janeiro. Portal Band, 04 mai. 2016. Disponível em: https://bit.ly/2Y67zdP. Acesso em: 23 ago. 2017

CHIZZOTTI, Antonio; PONCE, Branca Jurema. O currículo e os sistemas de ensino no Brasil. Currículo sem fronteiras, v. 12, n. 3, p. 25-36, 2012.

DAYRELL, Juarez. O jovem como sujeito social. Revista Brasileira de Educação, n. 24, Rio de Janeiro, set./dez. 2003.

DOYLE, A. Competência crítica em informação nas escolas ocupadas do Rio de Janeiro. Dissertação (Mestrado) - Universidade Federal do Rio de Janeiro, Escola de Comunicação, Instituto Brasileiro de Informação em Ciência e Tecnologia, Programa de Pós Graduação em Ciência da Informação, 2017.

GOMES, L. A. de O. Jovens trabalhadores-estudantes: a construção da vontade coletiva em experiências de ocupação de escolas. Dissertação (Mestrado), do Programa de Pós-Graduação em Educação da Faculdade de Educação, Universidade Federal Fluminense - Niterói - RJ, 2018.

NICODEMOS, Alessandra. Juventude na EJA: Desafios atuais. In: Seminário do Laboratório de Investigação, Ensino e Extensão em Educação de Jovens e Adultos, 2, 201, Rio de Janeiro. Anais... Rio de Janeiro, 2017. p. 172-174.

OLIVEIRA, Nicole Nöthen de. Por uma democracia para a educação: autonomia, liberdade e governo de si nas ocupações secundaristas de São Paulo. Tese de Doutorado em Psicologia, Instituto de Psicologia, Universidade de São Paulo, São Paulo, 2019.

PEREGRINO, M. Desigualdade, juventude e escola: uma análise de trajetórias institucionais. Pesquisas em Educação, n. 03. Niterói: EdUFF, 2008.

TARDIF, Maurice; LESSARD, Claude. A escola como organização do trabalho docente in: TARDIF; LESSARD. 0 Trabalho Docente. Rio de Janeiro: Vozes, p. 55-80, 2009. 